
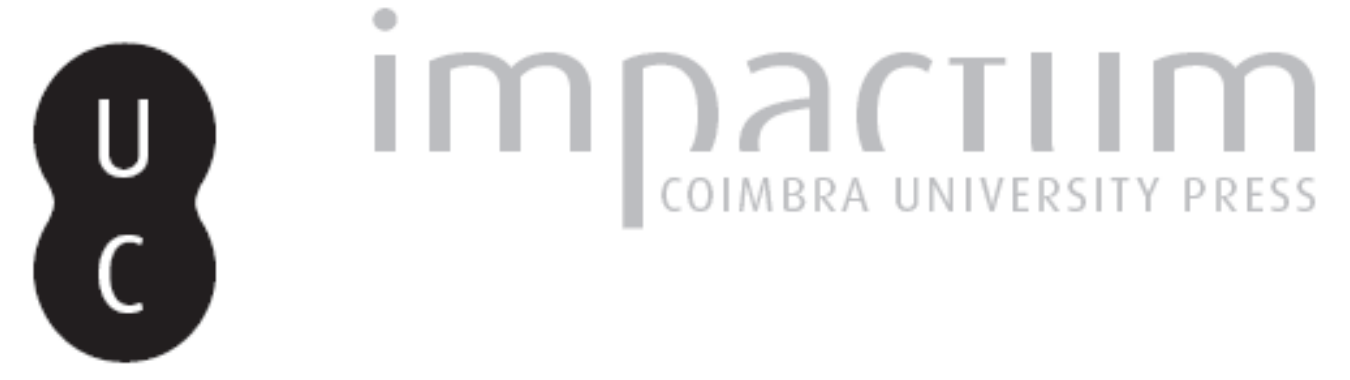

\title{
[Recensão a] Castilla y el Mundo Feudal. Homenaje al Professor Julio ValdeónValdeón, 3 volumes. Dir. de M.a Isabel del Val Valdivieso y Pascual Martínez Sopena
}
Autor(es):
Rocha, Ana Rita
Publicado por:
Faculdade de Letras da Universidade de Coimbra, Instituto de História
URL persistente: Económica e Social
DOI:
URI:http://hdl.handle.net/10316.2/28383
DOI:http://dx.doi.org/10.14195/0870-4147_43_17
Accessed : $\quad$ 26-Apr-2023 12:18:24

A navegação consulta e descarregamento dos títulos inseridos nas Bibliotecas Digitais UC Digitalis, UC Pombalina e UC Impactum, pressupõem a aceitação plena e sem reservas dos Termos e Condições de Uso destas Bibliotecas Digitais, disponíveis em https://digitalis.uc.pt/pt-pt/termos.

Conforme exposto nos referidos Termos e Condições de Uso, o descarregamento de títulos de acesso restrito requer uma licença válida de autorização devendo o utilizador aceder ao(s) documento(s) a partir de um endereço de IP da instituição detentora da supramencionada licença.

Ao utilizador é apenas permitido o descarregamento para uso pessoal, pelo que o emprego do(s) título(s) descarregado(s) para outro fim, designadamente comercial, carece de autorização do respetivo autor ou editor da obra.

Na medida em que todas as obras da UC Digitalis se encontram protegidas pelo Código do Direito de Autor e Direitos Conexos e demais legislação aplicável, toda a cópia, parcial ou total, deste documento, nos casos em que é legalmente admitida, deverá conter ou fazer-se acompanhar por este aviso.

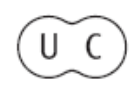


adoptada servem todos os públicos, mesmo os que não estejam directamente ligados à problemática arqueológica.

Justo é salientar, por fim, que se trata, na verdade, de uma investigação feita em equipa, coordenada pela catedrática de Arqueologia, Doutora Maria Manuela Martins. Os outros autores merecem também generoso encómio: José Meireles, Luís Fontes, Maria do Carmo Ribeiro, Fernanda Magalhães e Cristina Braga - cada um especialista em determinada época da História, que assim deram ao livro precioso contributo.

José d'Encarnação

Universidade de Coimbra

Castilla y el Mundo Feudal. Homenaje al Professor Julio Valdeón, 3

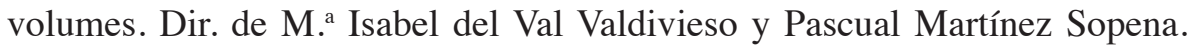
Valladolid: Junta de Castilla y Léon, Consejería de Cultura y Turismo e Universidad de Valladolid, 2009, 2073 p.

Castilla y el Mundo Feudal corresponde a uma colectânea de mais de cento e trinta artigos, divididos por três volumes, reunidos com o objectivo de prestar homenagem ao reputado medievalista Julio Valdeón, professor catedrático da Universidade de Valladolid, falecido em 2009. Dirigida por Maria Isabel del Val Valdivieso e Pascual Martínez Sopena, eles próprios discípulos do professor homenageado, a obra contou com uma forte adesão de mais de uma centena de autores, que trataram os mais diversos temas da medievalidade hispânica, a maior parte integrada nas questões estudadas e desenvolvidas por Julio Valdeón ao longo da sua carreira de investigador.

Esta colectânea inicia-se com uma introdução de Maria Isabel del Val Valdivieso, que nela traça, brevemente, o perfil académico e historiográfico do Professor Julio Valdeón, dando a conhecer os principais vectores do seu percurso intelectual. Assim, e complementando a informação com o currículo do Professor, também aqui descrito, importa destacar algumas dos momentos mais importantes da sua carreira, para compreender as bases em que a obra em análise assenta.

Julio Valdeón doutorou-se em 1965, com uma tese sobre Henrique II de Castela, primeiro rei da dinastia de Trastâmara, publicada um ano mais tarde com o título Enrique II de Castilla: la guerra civil y la consolidación 
del régimen (1366-1371)1. Esta primeira obra marcou a trajectória da sua produção historiográfica, que se centrou, assim, na Baixa Idade Média. Mas a sua investigação avançou por outros temas, de igual importância, que definiram também a sua carreira. Em 1975, altura em que a Espanha saía da ditadura, publicou Los conflictos sociales en el reino de Castilla en los siglos XIV y XV ${ }^{2}$, que abriu novos caminhos de investigação no panorama historiográfico medieval e ofereceu alternativas à corrente dominante. Destacou-se, ainda, na área da Teoria da História, disciplina que leccionou em Valladolid, transformando-a numa "auténtica herramienta de renovación historiográfica" (M. ${ }^{a}$ Isabel del Val Valdivieso, vol. I, p. 8). Da sua dedicação a esta matéria resultou uma colectânea de artigos sobre a História e o seu ensino, intitulada En Defensa de la Historia $(1988)^{3}$.

Jubilado em 2006, Julio Valdeón, ao longo da sua vasta carreira, publicou mais de vinte e cinco livros e cerca de duzentos artigos, orientou dezoito teses de doutoramento, algumas das quais renovaram a historiografia espanhola, e preocupou-se em transmitir a História, ao público em geral, com o máximo rigor científico, sendo uma referência incontestável para o estudo da Idade Média hispânica. A sua carreira e profissionalismo foram reconhecidos através da atribuição de vários prémios e da sua eleição, em 2001, como membro de número da Real Academia de la Historia.

Tendo como base a historiografia de Julio Valdeón, os artigos que compõem a obra em análise foram distribuídos por oito partes, organizadas por temas. Segundo Pascual Martínez Sopena, na descrição inicial da obra, os artigos de cada secção cumprem alguns critérios de ordem, a saber, cronologia e espaço, sentido mais geral ou concreto dos estudos, e problemas tratados. Passemos, então, à análise de cada uma das secções.

A primeira parte, intitulada "Fuentes, Debates y Percepciones de la Edad Media", é composta por dezanove artigos, onde são visíveis os principais interesses de Julio Valdeón na área da Teoria da História. Alguns dos artigos analisam as fontes e abordam os trabalhos daqueles que a elas se dedicam, como arqueólogos e diplomatistas. Nos restantes debatem-se as grandes interpretações da História, as orientações recentes da historiografia e a transmissão do conhecimento.

No caso dos primeiros, na maior parte, os autores apresentam fontes para o estudo da História Medieval, focando-se nas suas potencialidades, algumas

\footnotetext{
Valladolid: Universidad de Valladolid, 1966.

Madrid: Siglo XXI, 1975.

Valladolid: Ámbito, 1988.
} 
delas inovadoras, e o que pode ser estudado a partir delas. Tomemos como exemplo o estudo de Ricardo Izquierdo Benito ("Arqueología y fuentes escritas: el ejemplo de Las Partidas”, vol. I, p. 161-173), que apresenta uma forma de conciliação entre a arqueologia e as fontes escritas. Baseando-se em Las Partidas de Afonso X, fonte jurídica do século XIII, o autor demonstra como, para obter a máxima informação sobre a cultura material, o arqueólogo deve conjugar a que é transmitida pelos trabalhos de campo com a que as fontes escritas contêm. Num outro artigo, entre os vários que se incluem neste grupo que estuda as fontes, da autoria de José Antonio Munita Loinaz e José Ramón Díaz de Durana, intitulado "El archivo familiar de los Barroeta de Marquina: aportaciones para la reconstrucción de un conflicto banderizo en los confines de Vizcaya" (vol. I, p. 239-251), privilegia-se a documentação de um arquivo familiar (dos Barroeta y Gaitán de Ayala, na vila de Marquina, na Biscaia) para a análise e reconstrução de um conflito de bandos na Biscaia, nos finais da Idade Média, que opôs a mencionada linhagem dos Barroeta à dos Ugarte.

No que diz respeito ao segundo grupo de artigos contidos nesta primeira parte, os autores procuraram apresentar temas actuais da historiografia medieval, propondo as suas interpretações, mas também a evolução dos estudos medievais e a transmissão do conhecimento histórico, quer através do ensino, quer através da literatura. Deste modo, encontramos artigos como o de Assunción Esteban Recio, sobre os conflitos sociais e as heresias na Idade Média ("Conflictos sociales y herejías en la Edad Media”, vol. I, p. 49-67), e o de María Milagros Rivera Garretas ("La categoría marginación ¿oculta historia de las mujeres?", vol. I, p. 69-75), dedicado ao estudo das mulheres, ambos apresentando temas historiográficos recentes na área da História Social. Por sua vez, Ana Rodriguez López, no artigo intitulado "Parentesco, memoria y poder. Una aproximación a los debates recientes sobre la Edad Media" (vol. I, p. 77-94), apresenta uma maior diversidade de assuntos que têm vindo a ser desenvolvidos pelos medievalistas espanhóis, ingleses, franceses, entre outros, integrando-os nas grandes correntes historiográficas e traçando o seu estado da arte.

Nesta primeira secção, e ainda a respeito dos estudos sobre a historiografia medieval actual e conhecimentos sobre Idade Média, devemos salientar também os artigos de Martín F. Ríos Saloma e de Emilio Olmos Herguedas. O primeiro autor, no artigo "Notas sobre los estudios medievales en México" (vol. I, p. 111-132), escreveu sobre os estudos medievais no México, fazendo um balanço dos principais trabalhos feitos nesta área, contemplando o trabalho editorial, cursos e seminários, colóquios e encontros e exposições sobre a Idade Média.

Por sua vez, Emilio Olmos Herguedas, num artigo intitulado “¿Qué saben los adolescentes sobre la Edad Media? Contenidos curriculares y materiales 
didácticos al final de la educación obligatoria en Francia, Italia y Portugal" (vol. I, p. 133-146), pretendeu dar resposta a uma questão que se impõe: "¿qué ha sucedido com la presencia de la Edad Media en nuestra enseñanza obligatoria pre-universitaria?" (vol. I, p. 133). O autor começa por descrever os sistemas educativos nos três países em estudo, França, Itália e Portugal (escolhidos pela sua proximidade a Espanha). Segue-se a análise da presença da Idade Média nos conteúdos curriculares do ensino básico (frequentado por crianças e adolescentes, aproximadamente, entre os 10 e os 15 anos), dando ênfase aos principais temas de História Medieval que os compõem. Por fim, o autor estabelece uma relação entre a Idade Média e os materiais didácticos, com a qual pretende compreender até que ponto a época em estudo está presente.

A segunda secção, intitulada "Los Señores y los Señorios" reúne onze artigos e corresponde, mais uma vez, a um dos assuntos a que Julio Valdeón se dedicou, destacando-se um dos seus mais importantes estudos, "Señores y campesinos en la Castilla medieval". Este artigo resultou da conferência proferida no Congreso de Historia de Castilla y León (1982), cujas actas foram publicadas no ano seguinte, sob o título El pasado histórico de Castilla y León ${ }^{4}$.

A maioria dos artigos selecionados para compor esta parte da obra diz respeito a linhagens laicas e senhorios abadengos. Seguindo a opinião de Pascual Martínez Sopena, com estes dois grupos de artigos (senhorios eclesiásticos e laicos) é possível observar o contraste entre o tempo lento dos domínios da Igreja, como se observa nos mosteiros estudados, e o rápido desenvolvimento das linhagens laicas. Além dos artigos distribuídos por estas duas categorias de senhorios, foi ainda publicado um sobre Don Álvaro Pérez de Biedma, bispo do século XIV, e outro sobre a capela do condestável D. Pedro Fernández de Velasco (século XV), na catedral de Burgos. Importa destacar os dois grupos mencionados atrás, os senhorios eclesiásticos, com enfoque nos mosteiros, e os laicos.

Num primeiro grupo de artigos são estudados diversos mosteiros espanhóis, sob diferentes perspectivas: San Antolín de Bedón, Sant Cugat del Vallés, Santa Maria de Huerta, San Juan de Ortega, San Román de Peñas e Nuestra Señora del Brezo. O primeiro e o terceiro destes mosteiros foram estudados de um ponto de vista geral. Os autores, Juan Ignacio Ruiz de la Peña Solar (“El monasterio de San Antolín de Bedón en la Edad Media”, vol. I, p. 289-301)

${ }^{4}$ El pasado histórico de Castilla y León. $1 .{ }^{e r}$ Congreso de Historia de Castilla y León. 3 vols. Burgos: Junta de Castilla y León, Consejería de Educación y Cultura, 1983. 
e Luis Martínez García ("El monasterio de San Juan de Ortega. Relato breve de un señorío abadengo castellano en el Camino de Santiago (siglos XII-XV)", vol. I, p. 341-353), optaram por dar a conhecer as instituições, desde a sua fundação até aos séculos XV/XVI. No caso do mosteiro de Sant Cugat del Vallés (Motoki Murakami, "La formación de relaciones individuales en torno al monaterio de Sant Cugat del Vallés en la sociedad local hacia el año mil", vol. I, p. 303-312), a sua análise pautou-se, essencialmente, pelas relações que se estabeleceram entre a nobreza local e que afectaram a política da instituição. Por fim, tanto o autor do artigo sobre Santa Maria de Huerta (Nicolás Avila Seoane, "Señoríos del monasterio de Santa María de Huerta", vol. I, p. 313-330), como o daquele sobre os dois últimos mosteiros (Julio Antonio Pérez Celada, "La propiedad señorial y su gestión en el norte palentino a mediados del siglo XVI: San Román de Peñas y Nuestra Señora del Brezo", vol. I, p. 355-373) estudaram os domínios senhoriais dos cenóbios.

Aos artigos sobre senhorios abadengos acrescem aqueles que se dedicam aos senhorios laicos, num total de quatro, excluindo o que estuda a capela do condestável na catedral de Burgos. Neste pequeno grupo, encontramos estudos que analisam diversas linhagens medievais de Castela, a saber, a de Villanueva de Gómez (de Ávila), a Casa de Guevara (de Álava), a de Carrillo de Albornoz (de Cuenca) e a de Fernando de Antequera, neste caso centrada na figura de um dos seus membros. Apesar de abordarem um tema central comum, o dos senhorios laicos, centrados numa linhagem, estes artigos estudam o seu próprio tema de maneiras específicas e focando aspectos diferentes. Neste sentido, saliente-se, por exemplo, o artigo de Jose Ignacio Moreno Nuñez ("De nuevo sobre mayorazgos arcaicos en Castilla: el caso del llamado mayorazgo de Villanueva de Gómez (Ávila)", vol. I, p. 375-385), que, dando continuidade a um outro publicado em 1984, intitulado "Mayorazgos arcaicos en Castilla", analisa o problema do aparecimento e evolução do mayorazgo (correspondente ao morgadio em Portugal) em Castela, partindo da instituição do de Villanueva, em Ávila, considerado precoce, no século XIV.

Segue-se a esta secção uma terceira intitulada "El Mundo Urbano y el Comercio", composta por um total de quinze artigos. Como o título indica, esta parte reúne estudos sobre o mundo urbano na Península Ibérica e as dinâmicas económicas e comerciais, incluindo temas como a demografia, prosopografia, vitalidade das relações mercantis, ofícios urbanos, entre outros. Todos estes assuntos, relacionados com o mundo urbano, enquadram-se perfeitamente numa obra em homenagem a Julio Valdeón, pois ele próprio os estudou. Relembrem-se os seus estudos de caso das cidades de Murcia, Burgos e Valladolid e outros de temas mais específicos, entre os quais o das oligarquias urbanas. 
Os vários artigos incluídos na terceira secção focam diversas vertentes da história urbana, tal como foi mencionado. Encontramos, assim, dois trabalhos sobre prosopografia, um deles versando as carreiras eclesiásticas e redes sociais dos primeiros arcediagos leoneses, de Carlos Reglero de la Fuente ("Los primeros arcedianos leoneses (1070-1181): carreras eclesiásticas y redes sociales", vol. I, p. 503-519), e outro a família dos Oromir, nos séculos XIII e XIV, da autoria de Carme Batlle Gallart ("Los Oromir, de la villa de Tárrega (Lleida) a la ciudad de Barcelona (1214-1329)", vol. I, p. 521-537), que nos permite ter uma perspectiva da sociedade urbana medieval da Catalunha. Dois outros artigos dedicam-se a estudos de caso, abordando as cidades de Tarragona (Maria Bonet Donato, "Un centro económico regional: Tarragona en el siglo XV”, vol.I, p. 565-583) e de Cuenca (José María Sánchez Benito, "Aproximación a los movimientos de población a través de los avecindamientos: la ciudad y tierra de Cuenca en el siglo XV", vol. I, p. 585-597), a primeira sob o ponto de vista económico e a segunda sob o ponto de vista demográfico. Acrescem a estes, ainda, um estudo sobre a utilização do sumagre nos curtumes e tinturaria (Ricardo Córdoba de la Llave, "El zumaque, planta mediterránea, curtiente y tinte en la España medieval", vol. I, p. 455-468), outro sobre planificação urbana em Castela (Pascual Martínez Sopena, "Villas nuevas y planificación urbana en la Castilla medieval", vol. I, p.469-484), um terceiro dedicado às Cortes em Burgos (1391-1392) (Yolanda Guerrero Navarrete, "Identidad y "honor" urbano: Cortes en Burgos, 1391-1392", vol. I, p. 551-563) e um outro relativo ao testamento de uma mulher de Valladolid, do século XV, incidindo sobre um pequeno negócio de vinho que detinha e a prática do empréstimo (María Asenjo González, "Negocio y préstamo. Detalles del testamento de una mujer vallisoletana a mediados del siglo XV", vol. I, p. 599-614).

Mas o tema mais frequente na secção "El Mundo Urbano y el Comercio" é o comércio e as relações mercantis. Inclusivamente, como vimos, alguns dos artigos atrás referidos tratam também estes aspectos. Três dos estudos incluídos nesta parte da obra analisam as redes comerciais estabelecidas ao longo da Idade Média. No caso do artigo de Jesús Ángel Solórzano Telechea ("Villas y redes portuarias en la fachada Atlántica del Norte peninsular en la Edad Media", vol. I, p. 485-502), o autor salienta o papel das vilas e redes portuárias na abertura ao comércio externo, centrando-se, geograficamente, no norte atlântico da Península Ibérica; analisa também a intervenção régia nestas vilas portuárias e o desenvolvimento de redes urbanas entre elas. Os restantes artigos dedicam-se ao estudo do comércio, designadamente ao trato externo do vinho, às companhias comerciais castelhanas na Baixa Idade Média e ao comércio andaluz nos inícios do século XVI, estudado a partir 
de fontes fiscais. Por fim, devemos destacar o trabalho de Violeta Medrano Fernández ("Actos piráticos entre castellanos y portugueses y su reflejo en el comercio marítimo castellano-luso al final de la Edad Media", vol. I, p. 657-671), sobre actos de pirataria entre portugueses e castelhanos, uma vez que interessa, de uma forma mais directa, a investigadores do nosso país. Partindo de documentação relativa aos assaltos a navios que transportavam mercadorias entre os territórios castelhano e português, constituída na maior parte por denúncias, a autora procurou compreender o impacto da pirataria nas relações comerciais marítimas entre os dois reinos. Deste modo, começa por analisar os actos em si, as suas razões e o modo como se levavam a cabo, para em seguida salientar as suas consequências no comércio e descrever as medidas régias de ambas as coroas para combater a pirataria.

A quarta secção, que inicia o segundo volume, intitula-se "Fronteras y Herencias: Cristianos, Musulmanes y Judíos". A este tema, e em particular ao estudo dos Judeus, dedicou Julio Valdeón alguns dos seus trabalhos, entre os quais a obra Judíos y conversos en la Castilla medieval, de 2000. Os artigos publicados nesta secção retomam a temática das três grandes religiões, assentando nas relações entre elas e abordando assuntos como o exercício de actividades comerciais, a descriminação local, os ambientes fronteiriços, as últimas conquistas a muçulmanos na Península Ibérica e as consequências da expulsão dos judeus, num tempo compreendido entre os séculos X e XVI e num espaço que se estende da Galiza a Granada. Apresentemos, então, alguns dos artigos mais significativos que compõem esta parte da obra.

Os dois primeiros analisam os três grupos religiosos em questão, sob o ponto de vista das suas relações e coexistência num mesmo espaço geográfico. No caso do primeiro ("Celanova de las tres culturas, siglos X-XI", vol.II,p.9-24), o autor, Carlos Barros, estuda a convivência entre cristãos, judeus e muçulmanos em torno do mosteiro de Celanova (próximo de Ourense, Galiza), fundado por S. Rosendo, no século X. Este estudo é, inclusivamente, relevante para os historiadores portugueses, uma vez que aborda a nobreza do território que viria a ser Portugal. Por sua vez, Jesús G. Peribáñez Otero, no artigo "Violencia y espacio urbano. La percepción espacial de las relaciones sociales entre judíos, mudéjares y cristianos en la Ribera del Duero burgalesa" (vol. II, p. 25-42), aborda os conflitos entre judeus, muçulmanos e cristãos na comarca de Ribera del Duero, com origem não apenas ideológico-religiosa, mas também socio-económica. Como o próprio autor indica, por um lado, é analisada a violência como "manifestación más radical de la conflictividad", por outro, procura-se entender de que modo esses conflitos são perceptíveis no espaço físico urbano (vol. II, p. 26). 
Segue-se um conjunto de artigos referentes apenas aos muçulmanos ou às relações destes com os cristãos, cuja cronologia se estende, em alguns casos, até aos inícios do século XVI, já depois da conquista de Granada. Entre este grupo de estudos encontram-se, por exemplo, dois relativos aos cativos, tanto cristãos em mãos de muçulmanos, como estes prisioneiros daqueles. Relativamente à primeira situação, Gerardo Rodríguez analisa, em "La vida cotidiana de los cautivos cristianos en manos de los musulmanes. Península Ibérica - Norte de África, siglos XV y XVI" (vol. II, p. 101-114), os principais aspectos da vida quotidiana dos cativos cristãos em território muçulmano: as condições de vida (extremamente duras), os trabalhos executados e as crenças e manifestações religiosas. No outro artigo dedicado a cativos, "El destino de los cautivos llegados a Córdoba tras la toma de Málaga" (vol. II, p. 115-126), Margarita Cabrera Sánchez parte das actas notariais conservadas em Córdova, de 1487 e 1488, para avaliar o destino dos cativos muçulmanos capturados durante a conquista de Málaga (1487), que se tornaram propriedade da Coroa e foram repartidos pela população cordovesa.

A quarta secção termina com oito artigos sobre os judeus em território hispânico. A variedade de assuntos neles abordados permite obter uma visão geral sobre a presença judaica nos reinos da Península Ibérica e sobre os principais aspectos que caracterizaram essa mesma presença. Por exemplo, logo no primeiro artigo deste conjunto ("El crédito judío en el reino de Navarra, según los padrones de deuda hebreos (1323-1328)", vol. II, p. 237-249), Juan Carrasco Pérez aborda o crédito judaico no reino de Navarra, na primeira metade do século XIV, a partir de uma fonte fiscal, os padrões de dívida, produzidos pelos próprios judeus, que consistem em cartas de dívida, onde se registavam as concessões de dinheiro. Por sua vez, José Hinojosa Montalvo dedica o seu artigo "Brujería y satanismo entre los judíos valencianos" (vol. II, p. 251-163) ao estudo da prática da bruxaria e satanismo entre os judeus de Valência, incidindo sobre a feitiçaria e magia e dando a conhecer um dos processos levantados nessa cidade. Um outro artigo, de Hipólito Rafael Oliva Herrer ("Judíos en el mundo rural castellano a fines de la Edad Media: Alvar Gómez del Castillo, antes Jacob Agay, en Torremormojón”, vol. II, p. 293-303), analisa a presença de uma família judaica, os Agay, no mundo rural castelhano, em Torremormojón, nos finais da Idade Média, e a sua inserção na vida quotidiana da vila. Por fim, importa salientar o artigo de Ángel Alcalá (“Algunos problemas pendientes en torno a la expulsión de los judíos de España: exageraciones y precisiones", vol. II, p. 333-354), no qual este autor se debruça sobre alguns problemas, ainda por esclarecer, relativos à expulsão dos judeus de Espanha. $\mathrm{O}$ autor organizou o seu artigo de acordo com as questões ainda pendentes, 
procurando para elas uma resposta e também desfazer algumas ideias erradas que acabaram por se enraizar.

Depois do conjunto de artigos dedicados às "três culturas", Castilla y el Mundo Feudal prossegue com uma secção que reúne estudos acerca de um dos temas presentes nas mais relevantes obras da carreira de Julio Valdeón. Intitulada "Los Reinos Hispánicos y los Instrumentos del Poder Regio", esta parte debruça-se sobre o poder régio, tema abordado pelo Professor Valdeón na sua tese de doutoramento, Enrique II de Castilla: la guerra civil y la consolidación del régimen (1366-1371), de 1966, e na obra Alfonso X el Sabio. La forja de la España moderna, de $2003^{5}$, que recebeu o Premio Nacional de Historia no ano seguinte. De um modo geral, os vinte e cinco artigos aqui reunidos estudam temas como a ideologia de cruzada e as relações com outros reinos, o ambiente familiar dos monarcas, as ambições falidas, os mecanismos de negociação e as facções, a fiscalidade, a milícia ou a jurisdição real, a propaganda política, a memória régia e a imagem dos reinos/reinados.

Nesta secção, diversos são os artigos que estudam as monarquias hispânicas, que vieram, mais tarde, a formar o reino de Espanha, onde se destacam trabalhos de reconhecidos historiadores, como o de Carlos de Ayala Martínez ("Alfonso VII y la Cruzada. Participación de los obispos en la ofensiva reconquistadora", vol. II, p. 513-529), dedicado ao reinado de Afonso VII de Leão e Castela (século XII), incidindo sobre o movimento de cruzada operado na Península Ibérica contra o domínio muçulmano. Partindo daqui, o autor foca a participação dos bispos nas campanhas do rei, para as quais contribuíram com contingentes neste movimento de cruzada ofensivo. Aqui encontramos também a homenagem a Julio Valdeón de um dos editores da obra em análise, Maria Isabel del Val Valdivieso, e de José Manuel Nieto Soria, autores, respectivamente, dos artigos "La memoria de Enrique II en las crónicas de Enrique IV" (vol. II, p. 595-607) e "El Auto de Ávila de 1420" (vol. II, p. 679-690). Entre os artigos respeitantes aos reinos hispânicos salienta-se, ainda, o de Adeline Rucquoi, "Nobleza y Monarquía en Castilla: ¿una ilusión?" (vol. II, p. 609-625). Neste estudo, a historiadora retoma o tema de trabalhos levados a cabo por outros autores, em que se questionavam as relações entre monarquia e nobreza, em Castela, ao longo do século XV, marcadas pelas lutas entre estes dois grupos. Assim, Adeline Rucquoi foca a sua atenção em "cada uno de los principales actores de la historia castellana del siglo XV" (vol. II, p. 611), o rei, as cidades e a nobreza, de modo a compreender a importância de cada um, concluindo

\footnotetext{
5 Madrid: Temas de Hoy, 2003.
} 
que, embora a nobreza tenha atingido um maior protagonismo económico, cultural e social, este grupo não conseguiu alcançar os objectivos da sua revolta contra a monarquia, ou seja, desempenhar um papel político mais activo.

Nesta secção foram incluídos também alguns artigos sobre Portugal ou sobre indivíduos portugueses nos reinos hispânicos, tanto de historiadores portugueses, como espanhóis, que se revelam de grande utilidade para os investigadores nacionais. Isabel Vaz de Freitas e Maria José Ferro Tavares são as autoras portuguesas que dão o seu contributo nesta parte da obra, dedicada ao poder régio. A primeira autora escreveu o artigo "A Espada de Santiago, o Velo de Ouro e a Jarreteira" (vol. II, p. 409-422), sobre a Ordem da Espada de Santiago, instituída por D. Afonso V, em 1459 ou 1460, após a conquista de Alcácer Ceguer, estabelecendo uma comparação entre esta ordem de cavalaria, a borgonhesa do Velo de Ouro e a inglesa da Jarreteira. Maria José Ferro Tavares, num artigo intitulado "A construção da imagem do poder do rei" (vol. II, p. 423-441), analisa a imagem que seria transmitida pelos monarcas portugueses aos seus súbditos, particularmente nos séculos XIV e XV. Para atingir o seu objectivo, a autora centrou-se em três aspectos essenciais da imagem do rei: a justiça, a defesa e expansão da fé e a majestade real.

Outros cinco artigos, de autores espanhóis, abordam aspectos relevantes da História de Portugal, centrando-se nas relações do reino lusitano com os reinos hispânicos. Dois deles focam as relações matrimoniais estabelecidas com Portugal, de onde saíam infantas para casar com os monarcas dos reinos vizinhos, Leão e Castela. Inés Calderón Medina, em "Las arras de doña Teresa. El tratado entre Alfonso IX de León y Sancho I de Portugal de 1194" (vol. II, p. 443-456), analisa o tratado estabelecido entre D. Sancho I de Portugal e Afonso IX de Leão, pelo qual chegaram a acordo relativamente à gestão das arras da infanta D. Teresa, após a anulação eclesiástica do seu matrimónio com o referido rei de Leão. Por sua vez, César González Mínguez, no artigo “Constanza de Portugal, reina de Castilla (1290-1313)" (vol. II, p. 479-502), foca a sua atenção numa outra infanta portuguesa, que veio a ser rainha de Castela, D. Constança (1290-1313), filha de D. Dinis. O autor traça, neste artigo, o perfil biográfico da rainha, ao longo do reinado de seu marido, Fernando IV de Castela, e dos primeiros meses do de seu filho, Afonso XI, recorrendo, sobretudo, a documentação publicada.

Para finalizar a descrição da quinta secção, mencionemos apenas mais três artigos referentes às relações de Portugal com os reinos hispânicos: "Objetivos y proyectos en las relaciones castellano-portuguesas”, de Vicente Ángel Álvarez Palenzuela (vol. II, p.457-477); "Apoyo del partido português a una política pro-lusitana en Castilla durante el siglo XV”, de Paz Romero Portilla (vol. II, p. 665- 
-677); e "El magnífico señor don Álvaro de Portugal, contador de Castilla. Una trayectoria político-administrativa”, de István Szászdi León-Borja (vol. II, p. 699-709). Esclareça-se, no caso deste último, que o indivíduo estudado é um filho do duque de Bragança, nascido em Ceuta, em meados do século XV.

A sexta parte da obra em análise intitula-se "La Crisis Bajomedieval y la Conflictividad Social" e integra dezassete artigos, divididos em dois grupos, de acordo com o tema geral que abordam: a crise que afectou os reinos ibéricos, nos finais da Idade Média, nos séculos XIV-XV e até XVI, e alguns casos de conflitos que se registaram nos mencionados reinos, com destaque para Castela. Assim como temos visto para as restantes secções, a temática desta foi igualmente estudada por Julio Valdeón, sobretudo na obra Los conflitos sociales en el reino de Castilla en los siglos XIV y XV, de 1975, período fortemente marcado por tensões sociais em Espanha, que muito influenciaram o autor.

No primeiro dos referidos grupos de artigos encontramos trabalhos sobre a crise da Baixa Idade Média em Castela, Aragão e Portugal. Os dois primeiros reportam-se ao caso castelhano. Hilario Casado Alonso analisa a problemática partindo de uma questão colocada logo no título: “¿Existió la crisis del siglo XIV? Consideraciones a partir de los datos de la contabilidade de la catedral de Burgos" (vol. III, p. 9-25). Recorrendo aos livros de contabilidade da catedral de Burgos como fonte, o autor revisita o tema da crise do século XIV com o intuito de demonstrar que esta centúria não foi marcada apenas pela recessão económica, registando-se também algum crescimento, como se verificou na cidade em estudo. Ainda relativamente a Castela, Ignacio Álvarez Borge, em "Notas sobre la historiografía reciente acerca de la crisis bajomedieval en Castilla la Vieja" (vol. III, p. 27-40), debruça-se sobre a historiografia produzida nas últimas décadas sobre a crise naquele reino, de que considera os trabalhos de Julio Valdeón como ponto de partida. Segue-se o artigo de Esteban Sarasa Sánchez ("Recesión económica, crisis estructural y antagonismo social en Aragón a finales del siglo XIII y comienzos del XIV", vol. III, p. 41-52), onde é analisada a recessão económica e crise social em Aragão, entre os finais do século XIII e inícios do XIV. Por último, neste grupo, e com grande importância para a historiografia portuguesa, inclui-se um artigo de Humberto Baquero Moreno, intitulado "La crisis del siglo XIV en Portugal" (vol. III, p. 53-61), no qual o autor apresenta, a partir de elementos recolhidos em monografias sobre temas económicos e em documentação coeva, os sintomas da depressão económica europeia que se manifestaram em Portugal, a partir da guerra civil de 1319-1325 e ao longo do século XIV.

O segundo grupo é constituído, como já dissemos, por artigos nos quais são estudados, de forma mais pormenorizada, alguns conflitos registados na 
Península Ibérica, nos finais da Idade Média, sobretudo centrados na Castela rural e urbana. Dado o seu elevado número, seleccionamos apenas alguns artigos como exemplo. Certos trabalhos focam a sua atenção nos conflitos ocorridos no mundo rural, onde se destaca a força campesina, como no caso do artigo de Teófilo F. Ruiz, "Voices of the oppressed: peasant resistance in late medieval Castile" (vol. III, p. 63-72), onde o autor analisa diversos exemplos de resistência campesina contra a opressão senhorial, no norte de Castela, entre 1200 e o reinado dos Reis Católicos. Outros artigos debruçam-se sobre os poderes locais. Veja-se, a título de exemplo, o estudo de Carmen Díez Herrera sobre um conflito entre instituições de poder local, o mosteiro de Santo Toribio e a vila de Potes, na Cantábria ("Un ejemplo de enfrentamiento entre dos instituciones de poder local: el monasterio de Santo Toribio y la villa de Potes en la Baja Edad Media”, vol. III, p. 111-124). Salientem-se, ainda, os estudos dedicados aos enfrentamentos senhoriais, onde intervinham quer senhores eclesiásticos, quer nobres. Num artigo intitulado "Protesta popular y violencia institucional en la ciudad de Burgos a comienzos del siglo XVI: ingredientes de un conflicto sociorreligioso" (vol. III, p. 189-199), F. Javier Peña Pérez analisa o conflito, desencadeado em Burgos, que envolveu as autoridades religiosas, como o bispo da cidade e o abade do mosteiro de San Juan de Burgos, e os próprios paroquianos de San Lesmes, que se encontrava no centro da contenda, uma vez que as duas autoridades citadas lutavam pelo seu controlo jurisdicional. Aos conflitos entre senhores laicos dedicou-se José M. Monsalvo Antón, que estuda, no artigo aqui publicado, as lutas de bandos em Ciudad Rodrigo, durante a época Trastâmara, em que se opuseram algumas linhagens urbanas, que lutavam por um maior protagonismo no poder local.

Depois de reunidos, nas secções anteriores, artigos respeitantes aos principais temas da História Medieval, como a historiografia, os senhores e senhorios, o mundo urbano, os grupos religiosos, o poder régio e a crise dos finais da Idade Média, resta uma parte sobre a História Social e das Mentalidades, a sétima desta obra, a que se deu o título de "Cultura, Mentalidade y Vida Cotidiana". Segundo Pascual Martínez Sopena, no "Plan de la obra", aqui retomam-se, em parte, as temáticas dos artigos publicados no primeiro número da revista Edad Media $(1998)^{6}$, dedicado à cultura popular na Idade Média, cuja introdução é da autoria de Julio Valdeón. Encontramos, então, nesta secção, artigos que versam temas como as ideias universais, a memória e aprendizagem, as normas

\footnotetext{
${ }^{6}$ Edad Media. Revista de Historia, 1, 1998.
} 
de conduta, os marginais, a alimentação, a assistência, a vida religiosa e a peregrina, a morte, o tempo festivo, entre outros.

Os primeiros estudos incluídos nesta secção abordam as ideias universais, a memória e a aprendizagem, a partir de fontes monásticas e obras medievais. Entre estes artigos contam-se um de José Ángel Garcia de Cortázar e Leticia Agúndez San Miguel e outro de Miguel Ángel Ladero Quesada. Os autores do primeiro, intitulado "Memoria y cultura en la documentación del monasterio de Celanova: la respuesta de las "fórmulas inútiles" (años 842-1165)" (vol. III, p. 251-267), analisam a construção da memória histórica no mosteiro de Celanova, entre os anos de 842 e 1165, tal como já haviam feito para outros mosteiros, recorrendo às fórmulas diplomáticas dos documentos que compõem o tombo da instituição. No segundo artigo mencionado, "Gastar bien el tiempo y ordenar los oficios: consejos, instrucciones y ejemplos de Fray Hernando de Talavera" (vol. III, p. 269-294), Miguel Ángel Ladero Quesada analisa diversos escritos de Frei Hernando, prior do mosteiro de Nuestra Señora del Prado (Valladolid) e confessor de Isabel a Católica, nos quais o religioso discursa sobre o valor do tempo e dá conselhos sobre a sua rentabilidade. Deste modo, o autor organizou o artigo de acordo com os principais conselhos dados por Frei Hernando: o tempo "doméstico" da condessa de Benavente, D. María Pacheco, o tempo "político" da rainha Isabel, o tempo "enclausurado" das cistercienses e o tempo "pastoral” do arcebispo. Ladero Quesada conclui que os escritos em análise permitem conhecer diversos aspectos do quotidiano, mas também a personalidade do religioso que os escreveu, percebendo-se que tinha "gran claridade de ideas, visión de conjunto y sentido práctico" (vol. III, p. 294).

Entre os diversos temas que compõem a sétima secção, destaquemos ainda a assistência, onde se incluem dois artigos sobre hospitais medievais. O primeiro, "Control municipal y vida cotidiana en el hospital de Sant Llátzer de Valencia” (vol. III, p. 447-461), de Mercedes Gallent Marco, como o próprio título indica, consiste no estudo do hospital de leprosos de Valência, centrado na acção do poder municipal na instituição e no seu quotidiano, na centúria de Quatrocentos. Assim, a autora apresenta uma descrição dos aspectos mais relevantes do funcionamento deste hospital, tais como a sua administração, a alimentação dos enfermos, os seus rendimentos e até as condições materiais do edifício. No segundo artigo sobre assistência ("Beatriz de Portugal y el hospital Mater Dei de Tordesillas", vol. III, p. 463-477), Magdalena Santo Tomás Pérez debruça-se sobre o hospital Mater Dei de Tordesilhas e a problemática da sua fundação, no século XV, pela infanta D. Beatriz de Portugal, filha de D. Dinis, um dos filhos de D. Pedro e de D. Inês de Castro, dando a conhecer também alguns aspectos relativos ao funcionamento da instituição. 
Por último, nesta secção, seleccionamos ainda, para uma breve abordagem, o tema da vida religiosa. Sobre um dos aspectos da religião, nomeadamente da implantação da Igreja a nível local, fala-nos o artigo de María José Lop Otín, intitulado "Los estúdios sobre la vida parroquial castellana. Una aproximación desde la Edad Media" (vol. III, p. 525-540), que corresponde a um estudo e descrição da historiografia sobre o tema, enumerando as principais obras existentes, divididas em três grupos: obras gerais e de referência, histórias diocesanas e monografias. Num outro artigo ("Las capellanías de la iglesia de Lebrija (1476-1506)", vol. III, p. 541-548), Maria del Mar García Guzmán aborda as capelas fundadas na igreja de Lebrija, na diocese de Sevilha, a partir dos dois volumes de Livros de Visitas, datado o primeiro entre 1476 e 1500 , e o segundo de 1502 a 1506.

A obra Castilla y el Mundo Feudal termina com uma secção diferente de todas as outras, uma vez que é composta por artigos diversificados e sobre temas de outras épocas que não a Idade Média. Por isso mesmo recebeu o título de "Otros Ecos...". Nela se incluem trabalhos sobre Pré-História, Hispânia romana e século XVIII. Completam, ainda, esta secção duas pequenas homenagens a Julio Valdeón: uma memória da autoria de Luis Alberto de Cuenca ("Memoria de Julio Valdeón", vol. III, p. 639-640) e um poema de Juan José Molinero Martínez ("De mes, Julio", vol. III, p. 641).

Depois de uma incursão pela obra em análise, apresentando os principais assuntos nela abordados e alguns dos artigos mais relevantes, podemos concluir que Castilla y el Mundo Feudal constitui um riquíssimo manancial de informação respeitante à Idade Média ibérica. Nela são tratados os grandes temas que compõem a História Medieval, como a historiografia, o poder senhorial, o mundo urbano, o comércio, os grupos religiosos, o poder régio, a crise económica e social, a cultura, mentalidade e vida quotidiana, sendo útil a qualquer estudo sobre a Idade Média. Além disso, qualquer medievalista encontra aqui todo um conjunto de recursos úteis para os seus próprios trabalhos. De facto, muitos dos artigos coligidos foram enriquecidos com apêndices documentais e/ou gráficos e tabelas de interpretação, que facilitam a leitura do respectivo estudo, mas que também podem ser (re)utilizados por outros autores. Por tudo isto, os estudos em homenagem a Julio Valdeón constituem uma obra de incontornável consulta para quem se dedica à medievalidade ibérica nas suas múltiplas vertentes.

\section{Ana Rita Rocha}

Doutoranda em Altos Estudos em História - História da Idade Média

Faculdade de Letras da Universidade de Coimbra 